\title{
Especificidade de hospedeiro nas interações Xanthomonas campestris pv. campestris - brássicas*
}

\author{
Dulândula Silva Miguel-Wruck ${ }^{1 * *}$, José Rogério de Oliveira² \& Luiz Antônio dos Santos Dias ${ }^{3}$
}

${ }^{1}$ EPAMIG/CTTP, C.P. 351, CEP: 38001-970, Uberaba, MG, Brasil, C.P. 351, CEP: 38001-970, Uberaba, MG; ${ }^{2}$ UFV - Departamento de Fitopatologia, CEP 36571-000, Viçosa, MG, ${ }^{3}$ UFV - Departamento de Fitotecnia, CEP 36571-000, Viçosa, MG, 36570-001, Viçosa-MG.

* Parte da Tese de Doutorado do primeiro autor apresentada à Universidade Federal de Viçosa.

Autora para correspondência: Dulandula Silva Miguel-Wruck (dmiguel@epamiguberaba.com.br)

Data de chegada: 11/09/2008. Aceito para publicação em: 11/04/2010.

\section{RESUMO}

D. S. Miguel-Wruck, J.R. Oliveira \& L.A.S. Dias Especificidade de hospedeiro nas interações Xanthomonas campestris pv. campestris brássicas. Summa Phytopathologica, v.36, n.2, p.129-133, 2010.

Face às escassas informações acerca da variabilidade patogênica de isolados brasileiros de Xanthomonas campestris pv. campestris, realizou-se um estudo para avaliar a especificidade patogênica de trinta e três isolados do patógeno, provenientes de várias regiões do Brasil e do exterior, a oito espécies de brássicas, através de inoculação por meio de injeção da suspensão bacteriana nas folhas. Desse total, 12 isolados foram obtidos de couve-comum (Brassica oleracea var. acephala), nove de repolho ( $B$. oleracea var. capitata), cinco de couve-flor (B. oleracea var. botrytis), dois de canola (B. napus), um de brócolos (B. oleracea var. italica), um de couve-chinesa (B. chinensis), um de couve-rábano (B. oleracea var. gongylodes) e dois de rabanete (Raphanus sativus). A avaliação da patogenicidade dos isolados da bactéria, frente aos hospedeiros em estudo, demonstrou que 14 deles não apresentaram especificidade, originando sintomas em todas as diferentes plantas inoculadas. Os 19 isolados restantes, entretanto, apresentaram relativo grau de especificidade, não causando doença em uma ou mais das plantas inoculadas.

Palavras-chave adicionais: Podridão negra das crucíferas, variabilidade patogênica, brássicas, inoculação cruzada.

\section{ABSTRACT}

D. S. Miguel-Wruck, J.R. Oliveira \& L.A.S. Dias. Host specificity in interaction Xanthomonas campestris pv. campestris - brassicas. Summa Phytopathologica, v.36, n.2, p.129-133, 2010.

Considering the lack of information in literature about the pathogenic variability of Brazilian isolates of Xanthomonas campestris pv. campestris, a study was carried out to determine the pathogenic specificity of 33 isolates of this bacterium originated from several regions of Brazil and overseas to eight different Brassica species, through inoculation by means of injection of the bacterial suspension in leaves. From these isolates, 12 were obtained from collard greens (Brassica oleracea var. acephala), nine from cabbage (B. oleracea var. capitata), five from cauliflower ( $B$. oleracea var. botrytis), two from canola ( $B$. napus), one from broccoli (B. oleracea var. italica), one from Chinese cabbage (B. chinensis), one from kohlrabi (B. oleracea var. gongylodes) and two from radish (Raphanus sativus). The pathogenicity of the bacterium isolates to the tested hosts indicated that 14 of them were not specific and originated symptoms on all inoculated plants. The other 19 isolates had showed relative degrees of specificity and did not cause disease in one or more of the tested brassicas.

Keywords: Black rot disease of crucifers, brassicas, pathogenic variability, cross-inoculation.

A família Brassicaceae (ex. Cruciferae) compreende 3.500 espécies agrupadas em 350 gêneros, mas as espécies economicamente importantes estão no gênero Brassica: B. oleracea, B. napus, B. juncea e B. napus (19). Além de sua importância como hortaliças, essas espécies são utilizadas como adubo verde, forrageiras, condimentos e para a produção de óleo a partir das sementes (17).

No Brasil, os cultivos de brássicas têm maior expressão na região Centro-Sul, notadamente em São Paulo, Rio de Janeiro e Minas Gerais (15 e 17). Dentre as brássicas, o repolho, a couve comum, a couve-flor, o rabanete e o brócolos têm se expandido consideravelmente nos últimos anos. Somente o repolho foi comercializado nas Centrais de Abastecimento de Minas Gerais, em novembro de 2007 3,02 Mg, movimentando R \$ 968.000,00 (4).

A podridão negra, causada por Xanthomonas campestris pv. campestris (Pammel, 1895) Dowson 1939 (7) é, possivelmente, a doença mais importante das brássicas (20). A principal forma de disseminação do patógeno é por meio de sementes contaminadas (13). Portanto, um dos métodos mais eficientes de controle da doença é o uso de sementes livres do patógeno.

Embora seja um patógeno bastante estudado, as informações acerca da variabilidade patogênica de isolados brasileiros de X. campestris pv. campestris são escassas. O presente trabalho apresenta um estudo de especificidade de 33 isolados de Xanthomonas campestris pv. campestris frente a oito espécies de brássicas. 


\section{MATERIAL E MÉTODOS}

Para assegurar maior representatividade da variabilidade natural do patógeno, foram utilizados 33 isolados provenientes de várias localidades do Brasil e do exterior (Tabela 1) obtidos de oito espécies de brássicas: couve-comum (Brassica oleracea var. acephala), repolho (B. oleracea var. capitata), couve-flor (B. oleracea var. botrytis), canola (B. napus), brócolo (B. oleracea var. italica), couvechinesa (B. chinensis), couve-rábano (B. oleracea var. gongylodes) e rabanete (Raphanus sativus). Os isolados de X. campestris $p v$. campestris foram obtidos por doação de pesquisadores brasileiros e estrangeiros e por meio de isolamento nos Laboratórios de Bacteriologia de Plantas do Departamento de Fitopatologia da Universidade Federal de Viçosa (Tabela 1).

Cada um dos isolados teve sua patogenicidade e pureza verificadas sendo, posteriormente, caracterizados por provas bioquímicas, como descritas por Schaad \& Stall (14). Os isolados de $X$. campestris pv. campestris foram cultivados em placas de Petri contendo meio 523 de Kado \& Heskett (9). Após incubação a $28 \pm 1{ }^{\circ} \mathrm{C}$ por aproximadamente 24 horas, preparou-se uma suspensão bacteriana em solução salina ( $\mathrm{NaCl}$ 0,85\%), cuja concentração foi ajustada em um fotômetro Leitz para $\mathrm{OD}_{540}=0,30$.

Tabela 1. Dados dos isolados de Xanthomonas campestris pv. campestris utilizados para as análise patogênica em sete espécies de brássicas

\begin{tabular}{|c|c|c|c|c|}
\hline Código & Origem & Hospedeiro & Coleção & Instituição \\
\hline 1 & Paraná & Brassica napus & V.A. Malavolta Jr. & Instituto Biológico \\
\hline 2 & Paraná & B. napus & V.A. Malavolta Jr. & Instituto Biológico \\
\hline 3 & Minas Gerais & B. oleracea var. italica & A. Reis & CNPH/EMBRAPA \\
\hline 4 & Minas Gerais & B. oleracea var. acephala & D.S. Miguel-Wruck & UFV-EPAMIG \\
\hline 5 & Minas Gerais & B. oleracea var. acephala & A. Reis & CNPH/EMBRAPA \\
\hline 6 & São Paulo & B. oleracea var. acephala & D.S. Miguel-Wruck & UFV-EPAMIG \\
\hline 7 & Minas Gerais & B. oleracea var. acephala & D.S. Miguel-Wruck & UFV-EPAMIG \\
\hline 8 & Minas Gerais & B. oleracea var. acephala & R.M. Souza & UFLA \\
\hline 9 & Rio Grande do Sul & B. oleracea var. acephala & A.M. Bacarin & UFPEL \\
\hline 10 & Distrito Federal & B. oleracea var. acephala & C.A. Lopes & CNPH/EMBRAPA \\
\hline 11 & Distrito Federal & B. oleracea var. acephala & C.A. Lopes & CNPH/EMBRAPA \\
\hline 12 & Minas Gerais & B. oleracea var. acephala & D.S. Miguel-Wruck & UFV-EPAMIG \\
\hline 13 & Minas Gerais & B. oleracea var. acephala & D.S. Miguel-Wruck & UFV-EPAMIG \\
\hline 14 & São Paulo & B. oleracea var. acephala & L.O.S. Beriam & Instituto Biológico \\
\hline 15 & São Paulo & B. oleracea var. acephala & L.O.S. Beriam & Instituto Biológico \\
\hline 16 & São Paulo & B. chinensis & V.A. Malavolta Jr. & Instituto Biológico \\
\hline 17 & Espírito Santo & B. oleracea var. botrytis & D.S. Miguel-Wruck & UFV-EPAMIG \\
\hline 18 & Espírito Santo & B. oleracea var. botrytis & D.S. Miguel-Wruck & UFV-EPAMIG \\
\hline 19 & Minas Gerais & B. oleracea var. botrytis & A. Reis & CNPH/EMBRAPA \\
\hline 20 & Santa Catarina & B. oleracea var. botrytis & A. Reis & CNPH/EMBRAPA \\
\hline 21 & Minas Gerais & B. oleracea var. botrytis & A. Reis & CNPH/EMBRAPA \\
\hline 22 & São Paulo & B. oleracea var. gongyloides & V.A. Malavolta Jr. & Instituto Biológico \\
\hline 23 & Minas Gerais & R. sativus & D.S. Miguel-Wruck & UFV-EPAMIG \\
\hline 24 & Paraná & R. sativus & V.A. Malavolta Jr. & Instituto Biológico \\
\hline 25 & Espírito Santo & B. oleracea var. capitata & D.S. Miguel-Wruck & UFV-EPAMIG \\
\hline 26 & Minas Gerais & B. oleracea var. capitata & D.S. Miguel-Wruck & UFV-EPAMIG \\
\hline 27 & Santa Catarina & B. oleracea var. capitata & A. Reis & CNPH/EMBRAPA \\
\hline 28 & Minas Gerais & B. oleracea var. capitata & A. Reis & CNPH/EMBRAPA \\
\hline 29 & Espírito Santo & B. oleracea var. capitata & D.S. Miguel-Wruck & UFV-EPAMIG \\
\hline 30 & São Paulo & B. oleracea var. capitata & J.R. Neto & Instituto Biológico \\
\hline 31 & São Paulo & B. oleracea var. capitata & I.G.M. Almeida & Instituto Biológico \\
\hline 32 & EUA & B. oleracea var. capitata & T. Isakeit & Texas A\&M University, College Station \\
\hline 33 & EUA & B. oleracea var. capitata & T. Isakeit & Texas A\&M University, College Station \\
\hline
\end{tabular}

Os 33 isolados foram inoculados em todas as brássicas estudadas neste trabalho por meio de injeção da suspensão bacteriana nas folhas (2 a $3 \mathrm{~mL}$ ) (11). Após a inoculação, as plantas foram mantidas em casa de vegetação. Observações diárias foram realizadas para verificar o aparecimento dos sintomas e, posteriormente, foi realizado o teste de exsudação em gota, para comprovar a etiologia bacteriana das lesões.

Para classificar os diversos isolados avaliados quanto a especificidade de hospedeiro, utilizou-se a análise multivariada de agrupamento com auxílio do programa Statistica 5.1 (6). 


\section{RESULTADOS E DISCUSSÕES}

Com base nas análises de agrupamento (Figura 1), verifica-se a separação dos isolados de $X$. campestris pv. campestris em três grupos de similaridade. $\mathrm{Na}$ especificidade de hospedeiro o primeiro grupo foi composto pelos isolados 1 e 24 , que induziram sintomas somente em dois hospedeiros; o segundo grupo composto pelos isolados 2 (canola), 3, 4, 5, 6, 10, 11, 12, 14, 15 (couve), 23 (rabanete), 26, 27 e 31 (repolho), os quais induziram sintomas em todas as plantas hospedeiras; e, por último, um terceiro grupo de similaridade foi constituído pelos isolados restantes, que induziram sintomas em quatro a seis plantas hospedeiras.

Na literatura há relatos de que a bactéria se mostra altamente patogênica a várias brássicas em diferentes condições, porém estas condições não foram bem elucidadas (1 e 2). De acordo com Bradbury (3), X. campestris pv. campestris tem como hospedeiras várias brássicas, dentre elas a couve comum (Brassica oleracea var. acephala), o repolho (B. oleracea var. capitata), a couve-flor (B. oleracea var. botrytis), a canola (B. napus), o brócolos (B. oleracea var. italica), a couve-chinesa (B. chinensis), a couve-rábano (B. oleracea var. gongylodes) e o rabanete (Raphanus sativus). Entretanto, verificou-se pela inoculação cruzada (Tabela 2) que isolados de $X$. campestris pv. campestris podem apresentar especificidade de hospedeiro. Isso ocorre em razão, possivelmente, da variabilidade tanto do patógeno quanto do hospedeiro.

Dos 33 isolados estudados, todos patogênicos, 14 deles não apresentaram especificidade quanto aos hospedeiros, uma vez que induziram sintomas em todas as plantas inoculadas. No entanto, os 19 isolados restantes apresentaram relativo grau de especificidade, pois não causaram doença em uma ou mais das brássicas inoculadas (Tabela 2).

A ocorrência de especificidade entre os isolados não é um estudo isolado no Brasil, existem vários relatos de isolados de $X$. campestris causando doenças em diferentes espécies de brássicas em alguns países, como nos trabalhos realizados por Moffet et al. (12) e Zhao et al. (21) onde os autores relataram a primeira ocorrência da bactéria em couve flor, brócolos e repolho na Austrália e nos Estados Unidos respectivamente.

Yuen et al. (18), trabalhando com plantas de repolho, verificaram diferenças na icrulência e, ou, na capacidade de isolados de X.campestris pv. campestris de se disseminar, e consideraram que esses fatores podem levar a variações da intensidade da doença. Estudos posteriores, realizados por Chen et al. (5), permitiram verificar que $X$. campestris pv. campestris é genética e patogênicamente heterogênea. Aqueles autores verificaram, também, que a variação observada não foi revelada no desenvolvimento dos sintomas resultantes de inoculação em laboratório.

A especificidade por hospedeiro dos isolados usados nesse trabalho pode ser explicada também pela resistência de algumas cultivares à bactéria. No trabalho realizado por Vicente et al.(16), verificou-se que o locus Xca4 controla a resistência raça específica a X. campestris pv. campestris em nabo (Brassica napus).

Machado (1985) citado por Henz et al. (8) estudou 67 isolados de $X$. campestris pv. campestris provenientes de ervas daninhas. Dentre esses isolados, somente 15 foram patogênicos a brássicas, ressaltando-se que um dos isolados somente a repolho e, outro, somente a couve.

Existe também variação da virulência entre os isolados de $X$. campestris pv. campestris, esse dado foi observado por Henz et al. (8) no estudo da avaliação da virulência e variabilidade de 56 isolados brasileiros dessa bactéria onde os autores verificaram que, a virulência variou entre os isolados estudados, sendo encontrados dois isolados mais virulentos e dois menos virulentos.

A variação de virulência e de patogenicidade entre isolados de $X$. campestris pv. campestris pode ser explicado através do trabalho de Kamoun et al. (10). É sabido que o locus HrpXc é requerido para a patogenicidade de $X$. campestris pv. campestris em plantas hospedeiras e para a resposta de hipersensibilidade em plantas

Figura 1. Dendrograma de UPGMA referente a 33 isolados de Xanthomonas campestris pv. campestris avaliados com base na inoculação cruzada em sete diferentes espécies de brássicas.

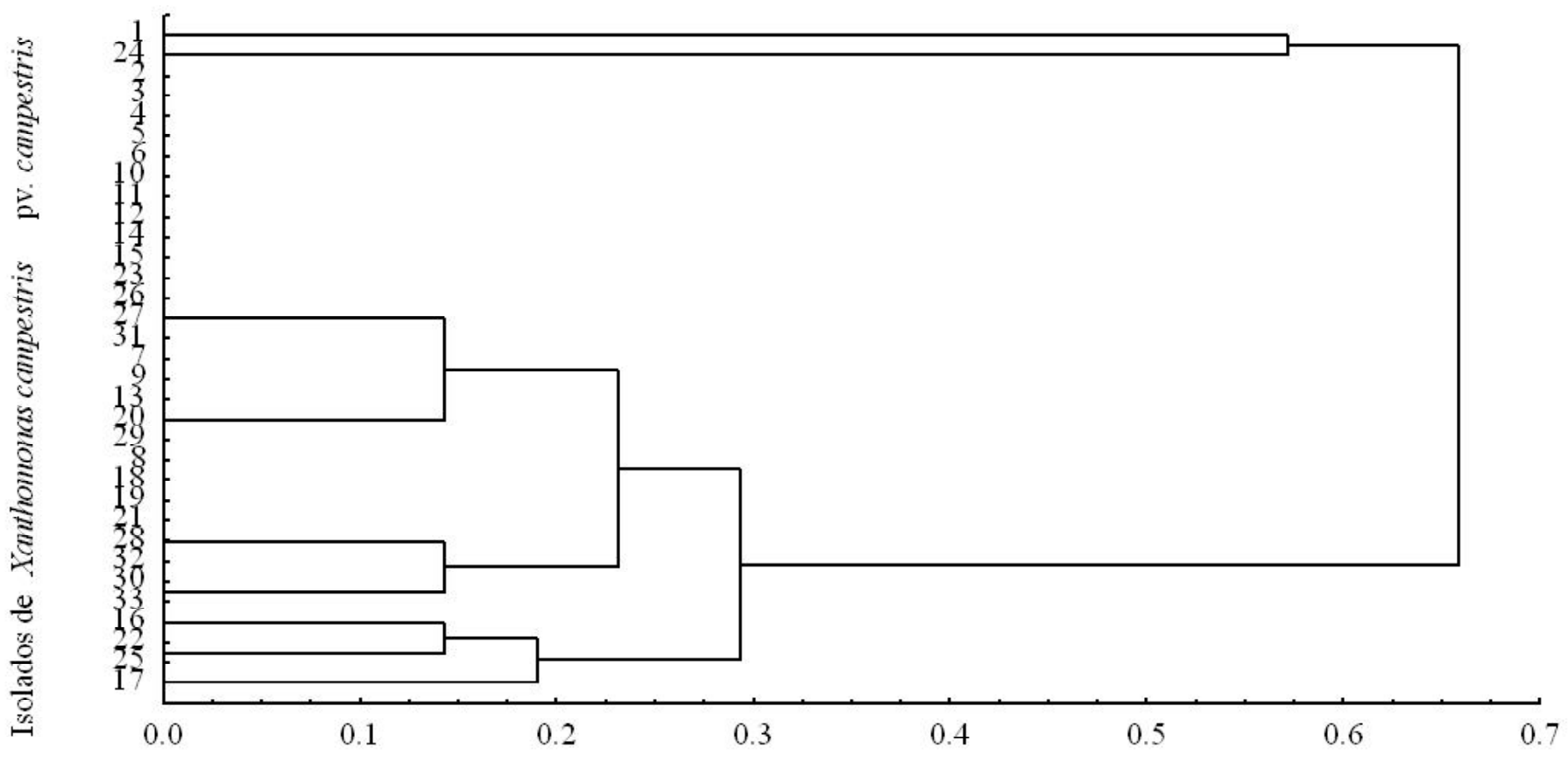

Distância de fusao 
não hospedeiras, porém, esses autores verificaram que o mesmo locus pode estar envolvido na supressão de resposta de defesa de plantas hospedeiras.

Existem relatos de pelo menos duas espécies de $X$. campestris além de $X$. campestris pv. campestris causando mancha nas folhas de brássicas; $X$. campestris pv. armoraciae e X. campestris pv. aberrans $(12,21)$

Durante a execução do presente trabalho, descartou-se a possibilidade de se estar trabalhando com isolados de $X$. campestris pv. armoraciae, uma bactéria também patogênica a brássicas e agente causal de manchas foliares. Embora não existam conhecimentos profundos das diferenças genéticas entre esses dois patovares (5), a hipótese de que alguns isolados pudessem pertencer a $X$. campestris pv. armoraciae foi descartada, pois, segundo Bradbury (3), essa bactéria só induz sintomas em brássicas quando inoculada artificialmente e os isolados utilizados neste trabalho foram todos obtidos de plantas naturalmente infectadas.

Mais estudos precisam ser realizados para se entender melhor a variação na especificidade dos isolados em relação às brássicas utilizadas neste trabalho. É importante, inclusive, um estudo para determinação das raças do patógeno de ocorrência no Brasil. Kamoun et al. (10) agruparam número limitado de isolados de $X$. campestris pv. campestris em cinco raças, de acordo com a resposta de diferentes cultivares de Brassica napus e B. juncea. Segundo esses autores, a estrutura de raça em populações de $X$. campestris pv. campestris varia consideravelmente entre países com extensas áreas de cultivo de brássicas.

Com base nos resultados encontrados, concluiu-se que a

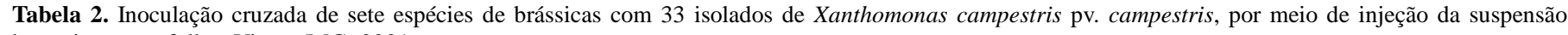
bacteriana nas folhas.Viçosa/MG, 2001.

\begin{tabular}{|c|c|c|c|c|c|c|c|}
\hline \multirow[b]{2}{*}{ Isolados } & \multirow[b]{2}{*}{$\begin{array}{c}\text { B. oleracea } \\
\text { var. acephala }\end{array}$} & \multicolumn{5}{|c|}{ Hospedeiros } & \multirow[b]{2}{*}{ B. napus } \\
\hline & & $\begin{array}{l}\text { B. oleracea } \\
\text { var. botrytis }\end{array}$ & $\begin{array}{l}\text { Raphanus } \\
\text { sativus }\end{array}$ & B. chinensis & $\begin{array}{c}\text { B. oleracea } \\
\text { var. capitata }\end{array}$ & $\begin{array}{l}\text { B. oleracea } \\
\text { var. italica }\end{array}$ & \\
\hline 1 & $-^{11}$ & + & - & - & - & - & + \\
\hline 2 & + & + & + & + & + & + & + \\
\hline 3 & + & + & + & + & + & + & + \\
\hline 4 & + & + & + & + & + & + & + \\
\hline 5 & + & + & + & + & + & + & + \\
\hline 6 & + & + & + & + & + & + & + \\
\hline 7 & + & + & + & - & + & + & + \\
\hline 8 & + & + & + & - & + & + & - \\
\hline 9 & + & + & + & - & + & + & + \\
\hline 10 & + & + & + & + & + & + & + \\
\hline 11 & + & + & + & + & + & + & + \\
\hline 12 & + & + & + & + & + & + & + \\
\hline 13 & + & + & + & - & + & + & + \\
\hline 14 & + & + & + & + & + & + & + \\
\hline 15 & + & + & + & + & + & + & + \\
\hline 16 & + & + & - & + & + & + & - \\
\hline 17 & - & + & - & + & + & + & + \\
\hline 18 & + & + & + & - & + & + & - \\
\hline 19 & + & + & + & - & + & + & - \\
\hline 20 & + & + & + & - & + & + & + \\
\hline 21 & + & + & + & - & + & + & - \\
\hline 22 & + & + & - & + & + & + & + \\
\hline 23 & + & + & + & + & + & + & + \\
\hline 24 & - & - & + & - & + & - & - \\
\hline 25 & + & + & - & + & + & + & + \\
\hline 26 & + & + & + & + & + & + & + \\
\hline 27 & + & + & + & + & + & + & + \\
\hline 28 & + & + & + & - & + & + & - \\
\hline 29 & + & + & + & - & + & + & + \\
\hline 30 & + & + & + & + & + & + & - \\
\hline 31 & + & + & + & + & + & + & + \\
\hline 32 & + & + & + & - & + & + & - \\
\hline 33 & + & + & + & + & + & + & - \\
\hline
\end{tabular}

(+) $=$ lesões com necroses nos vasos e que mostraram exsudação ao microscópio e $(-)=$ ausência de lesões. 
especificidade dos isolados de X. campestris pv. campestris estudados não possui qualquer relação com a origem geográfica ou o hospedeiro do qual foram obtidos.

\section{Agradecimentos \\ Os autores agradecem à agência FAPEMIG.}

\section{REFERÊNCIAS BIBLIOGRÁFICAS}

1. Alvarez, A.M. \& Cho, J.J. Black rot of cabbage in Hawaii: inoculum source and disease incidence. Phytopathology, St. Paul, v.68, p.1456-1459, 1978.

2. Alvarez, A.M.; Benedict, A.A.; Mizumoto, C.Y.; Hunter, J.E.; Gabriel, D.W. Serological, pathological, and genetic diversity among strains of Xanthomonas campestris infecting crucifers. Phytopathology, St. Paul, v.84, n.12, p.1449-1457, 1994.

3. Bradbury, J.F. Guide to plant pathogenic bacteria. England: CBA International, 1986. 332p.

4. Analise Conjuntural. Contagem: CEASA Minas Gerais, Nov. de 2007. disponível em: 〈http://www.ceasaminas.com.br〉. Acesso em novembro de 2007.

5. Chen, J.; Roberts, P.D.; Gabriel, D.W. Effects of a virulence locus from Xanthomonas campestris $528^{\mathrm{T}}$ on pathovar status and ability to elicit blight symptoms on crucifers. Phytopathology, St. Paul, v.84, n.12, p.1458-1464, 1994.

6. Dias, L.A.S. Análises multidimensionais. In: Alfenas, AC. (Ed.) Eletroforese de isoenzimas: aplicação a microrganismos e plantas. Viçosa: Editora UFV, Viçosa, 1998, p. 405-475.

7. Fahy, R.C.; Persley, G.J. Plant bacterial diseases: - a diagnostic guide. Australia: Academic Press, 1983. 393p.

8. Henz, G.P.; Takatsu, A.; Reifschneider, F.J.B. Avaliação da virulência e variabilidade em isolados de Xanthomonas campestris pv. campestris. Fitopatologia Brasileira, Brasília, v.12:350$353,1987$.

9. Kado, C.I.; Heskett, M.G. Selective media for isolation of Agro- bacterium, Corynebacterium, Erwinia, Pseudomonas and Xanthomonas. Phytopathology, Saint Paul, v.60, p.969-976, 1970.

10. Kamoun, S.; Kandar, H.V.; Yolam, E.; Kado, C.I. Imcompatible interactions between crucifers and Xanthomonas campestris involve a vascular hypersensitive response: role of the hrpX locus. Molecular Plant- Microbe Interaction, v.5 (1):22-23, 1992.

11. Klement, Z.; Rudolph, K.; Sands, D.C. Methods in phytobacteriology. Budapest: Académiai Kiado, 1990. 568p.

12. Moffett, M.L.; Trimboli, D.; Bonner, I.A. A bacterial leaf spot disease of several Brassica varieties. AUSTRALIAN PLANT PATHOLOGY SOCIETY NEWSLETTER, 5:30-32, 1976.

13. Rodrigues Neto, J.; Malavolta Júnior, V.A. Doenças causadas por bactérias em crucíferas. Informe Agropecuário, Belo Horizonte, v.17, n.183, p.56-59, 1995.

14. Schaad, N.W.; Stall, R.E. Xanthomonas. In: SCHAAD, N.W. Laboratory guide for identification of plant pathogenic bacteria. St. Paul: APS Press., 1988. 158p.

15. Siqueira, T.S. Cultura de brássicas. Viçosa, MG: Imprensa Universitária. UFV. MG, 1981. 30p.

16. Vicente, J.G.; Taylor, J.D.; Sharpe, A.G.; Parkin, I.A.P.; Lydiate, D.J.; King, G.J. Inheritance of. race-specific resistance to Xanthomonas campestris pv. campestris in Brassica genomes. Phytopathology, St. Paul, v.92, p.1134-1141, 2002

17. Vilela, M.R. Brássicas, hortaliças de alto valor alimentício. Informe agropecuário, Belo Horizonte, v.9, n.98, 1983, 58p.

18. Yuen, G.Y., Alvarez, A.M., Benedict, A.A., Trotter, K.J. Use of monoclonal antibodies to monitor the dissemination of Xanthomonas campestris pv. campestris. Phytopathology, St Paul, v.77, p.366-370, 1987.

19. Warwick, S.I., Francis, A.; Fleche, J. LA. Guide to the Wild Germplasm of Brassica and Allied Crops (tribe Brassiceae, Brassicaceae) 2nd ed. Agriculture and Agri-Food Canada, Ottawa, Ontario: Eastern Cereal and Oilseeds Research Centre, 2000. Disponível em: <http://www.brassica.info/resources/ crucifer_genetics/guidewild.htm>. Acesso em: 5 set. 2007.

20. Williams, P.H. Black rot: a continuing threat to world crucifers. Plant Disease, St. Paul, v.64, p.736- 742, 1980.

21. Zhao, Y.; Damicone, J.P.; Demezas, D.H.; Bemder, C.L. Bacterial leaf spot leafy crucifers in Oklahoma caused by Xanthomonas campestris. Plant Disease, St. Paul, v.84, p.1008-1014, 2000. 